\title{
Transparent Perfluoropolyethers for Vacuum Ultraviolet Applications
}

\author{
Mattia Bassi,* Pier-Antonio Guarda, Elvira Pagano, Aldo Sanguineti, and \\ Giuseppe Marchionni
}

Solvay-Solexis R\&D Center, Viale Lombardia 20, Bollate, Milano I-20021, Italy

Received: January 11, 2006; In Final Form: April 11, 2006

\begin{abstract}
After a broad scouting based on quantum chemical calculations, optical absorption measurements in the vacuum ultraviolet (VUV) wavelength region between 140 and $190 \mathrm{~nm}$ were performed on a narrower series of commercial and experimental liquids. By elimination of sources of external contamination, mainly due to atmospheric gases, the analysis of the contributions to the absorption related to the backbone structure and to the chain end composition allowed the synthesis of a novel family of linear perfluoropolyethers (PFPEs) with optical absorbance at $157 \mathrm{~nm}$ between 0.3 and $0.6 \mathrm{~cm}^{-1}$ in a broad range of compositions and molecular weights. The dependence of the optical threshold on the PFPE composition demonstrates that $-\mathrm{OCF}_{2}-$ is the most transparent segmental unit in the VUV region.
\end{abstract}

\section{Introduction}

The synthesis of the ideal organic structure with the lowest absorption in the vacuum ultraviolet (VUV) wavelength region requires the comprehension of the dependence of the optical absorption on the structural composition. Moreover, the architecture of macromolecular species with optical properties independent of the molecular weight would allow the tuning of technologically relevant physical properties such as viscosity or vapor pressure without any optical drawbacks, thus extending the application opportunities when transparency in a broad spectral region from VUV to IR is required, for example, in experimental methods such as VUV dichroism spectroscopy ${ }^{1}$ and Cherenkov detection ${ }^{2,3}$ or in industrial processes such as laser micromachining ${ }^{4,5}$ and projection lithography. ${ }^{6}$

Immersion lithography has been demonstrated as the most promising technology to extend the limits of the optical lithography beyond critical dimensions (CDs) of $45 \mathrm{~nm} .{ }^{7-9}$ The interposition of a liquid between an exposure tool's projection lens and the wafer offers the opportunity for better resolution over conventional projection lithography because the optical system can be designed with a numerical aperture (NA) greater than one, thus creating the ability to produce smaller features.

If at $193 \mathrm{~nm}$ water is the natural candidate to implement the established tool infrastructures, then the extension of the immersion technology to $157 \mathrm{~nm}$ requires the development of a convenient, transparent fluid.

In a recent paper, the transparency between 150 and $200 \mathrm{~nm}$ of a wide series of fluorinated fluids, including perfluorinated polyethereal molecules, has been investigated. ${ }^{10}$ After careful removal of the external contaminants (mainly oxygen and water), recognized as the most important sources of optical absorption in the "as-received" liquids, an absorbance as low as $0.52 \mathrm{~cm}^{-1}$ has been reported on the purified perfluorotriglyme.

However, the intrinsic optical behavior of perfluorinated polyethereal structures has not been fully clarified, particularly as it concerns the source of the measured variable absorption coefficients at $157 \mathrm{~nm}$.

* Author to whom correspondence should be addressed. E-mail: mattia.bassi@solvay.com.
With the aim to evaluate the single molecular contributions to the VUV absorbance, the optical absorption between 140 and $190 \mathrm{~nm}$ has been measured on a series of fluoropolyethers with controlled structural differences. In particular the roles of the oxygen-to-carbon ratio, perfluoromethyl side groups, and the chain ends have been carefully investigated. We started from the available commercial polymers, connecting theoretical (highest occupied molecular orbital (HOMO)-lowest unoccupied molecular orbital (LUMO) energy gap) calculations and absorption measurements in the VUV region. The rationale behind this approach is that the energy gap can be directly related to the absorption edge in the VUV range, as has been already reported in the literature in the case of the absorption behavior of polytetrafluoethylene. ${ }^{11}$

The presence of oxygen in PFPE molecules has been reported to have a strong impact on chain flexibility without substantially changing the overall polarity of the molecule in comparison with perfluoralkyl analogues. As a consequence, the glass transition temperature decreases with an increasing oxygen-tocarbon ratio, while maintaining a low cohesive energy density that is comparable to those of perfluoroalkanes. ${ }^{12}$ Side perfluoromethyl groups induce an increase of molecular stiffness, ${ }^{13}$ which in turn leads to a substantially higher $T_{\mathrm{g}}$ than that for linear PFPEs. ${ }^{12}$ The chain ends of PFPE molecules are usually perfluoromethyl groups; however, very small amounts of different end groups may be present, whose nature depends on the synthetic route. ${ }^{14}$

\section{Experimental Section}

2.1. UV Spectrophotomer. Experimental data were obtained from a series of transmittance measurements carried out on a VUV spectrometer operating in a vacuum $\left(10^{-4}\right.$ Torr $)$ in the Seya Namioka configuration, ${ }^{15}$ equipped with a $40 \mathrm{~W}$ lowpressure hydrogen lamp (McPherson model 630) and a concave aberration-corrected holographic diffraction grating with a rule of $1200 \mathrm{~mm}^{-1}$ (Bausch \& Lomb), which with the set input and output slits allowed a resolution of $<0.5 \mathrm{~nm}$. A quartz chopper allowed the continuous monitoring of the beam power. Normalizing the output of the signal detector with the reference detector removes time-dependent variations of the lamp intensity and 
increases the stability of the measurement. The spectral range for all the measurements was $140-220 \mathrm{~nm}$, and the repeatability of the transmittance values was around $1 \%$.

2.2. Optical Cells. All the measurements were obtained with some homemade transmittance cells. The basic cell was made by sandwiching the liquid between two optical windows with a toroidal spacer to create the proper optical path. The cell was tightened by two aluminum flanges. Several cells were built with different sizes and optical paths to tackle the problems arising from the wide range of viscosity, vapor pressure, and UV absorbance of the fluids. The optical windows were 2-mmthick UV-grade $\mathrm{CaF}_{2}$ made by St-Gobain, while the spacers were made of poly(tetrafluoroethylene) (ALGOFLON PTFE, SolvaySolexis). PTFE was chosen for its proper combination of chemical and mechanical properties, having good stability in contact with fluids and UV light and good sealing with low boiling point fluids. The spacer thickness was varied in the range between 100 and $4000 \mu \mathrm{m}$ to optimize the $I / I_{0}$ ratio in the $0.1-$ $100 \mathrm{~cm}^{-1}$ absorbance range. The accuracy of the thickness, which largely determines the experimental uncertainty of the transmittance, was about $5 \%$.

2.3. Absorbance Determination and Correction for Surface Reflection. The transmittance $T$ is calculated as the ratio of the measured transmittance of the sample $T_{\mathrm{s}}$ and transmittance $T_{\mathrm{w}}$ of the empty cell obtained from a blank measurement $(T=$ $T_{\mathrm{s}} / T_{\mathrm{w}}$ ). The absorbance (Abs) is calculated as Abs $=-1 / t \log -$ $(T)$, where $t$ is the optical path.

Before calculation of the absorbance, the transmittance loss from the two internal surfaces of the measuring cell was corrected to take into account the decrease in their reflectivity upon the insertion of a liquid sample into the cell. In fact, the reflectance at the interface between two media is a function of the angle of incidence $I_{1}$ and the angle of refraction $I_{2}$ as given by the Fresnel relationship

$$
R=\frac{1}{2}\left[\frac{\sin ^{2}\left(I_{1}-I_{2}\right)}{\sin ^{2}\left(I_{1}+I_{2}\right)}+\frac{\tan ^{2}\left(I_{1}-I_{2}\right)}{\tan ^{2}\left(I_{1}+I_{2}\right)}\right]
$$

The first term in eq 1 corresponds to the reflection that is polarized in the plane of the incidence, and the second term corresponds to the reflection in the perpendicular plane.

Thus, the reflectance at the interface between two media with refractive indices $n_{1}$ and $n_{2}$ at normal incidence is given as

$$
R=\left|\frac{n_{2}^{*}-n_{1}^{*}}{n_{2}^{*}+n_{1}^{*}}\right|^{2}
$$

where $n^{*}$ is the complex refractive index or $n-\mathrm{i} k$, where $n$ is the real refractive index and $k$ is the extinction coefficient. For nonabsorbing materials, $k=0$ and $n^{*}=n$, simplifying into

$$
R=\frac{\left(n_{2}-n_{1}\right)^{2}}{\left(n_{2}+n_{1}\right)^{2}}
$$

Thus, the amount of light reflected by the filled cell $\left(n_{2}=\right.$ $n_{\mathrm{CaF}_{2}} ; n_{1}=n_{\text {liquid }} \approx 1.3-1.4$ ) is less than the amount of light reflected by the empty cell $\left(n_{2}=n_{\mathrm{CaF}_{2}} ; n_{1}=1\right)$ used for the blank measurement. The actual transmittance of the sample is obtained by applying a correction factor (wavelength-dependent) function of the refraction index of $\mathrm{CaF}_{2}$ and of the liquid in the spectral range examined.

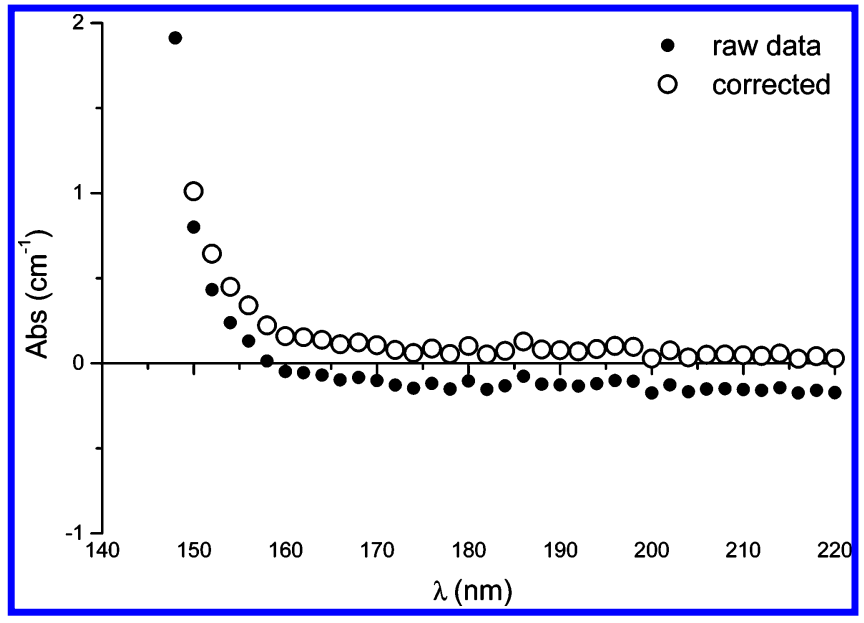

Figure 1. Absorbance of the experimental sample ZOG 2 before and after correction for the window reflectance.

Figure 1 shows the difference between the absorbance calculated from the raw transmittance data and that after application of the correction for the reflection from the internal cell surfaces. These data refer to a highly transparent experimental sample measured with an optical path of $1 \mathrm{~mm}$. It is evident that the uncorrected absorbance is negative for all those wavelengths where no absorption occurs. The uncorrected absorbance at $157 \mathrm{~nm}$ is $0.11 \mathrm{~cm}^{-1}$, corresponding to an uncorrected transmittance of $97.4 \%$ over $1 \mathrm{~mm}$. This figure can be compared with literature data obtained without taking into account this correction. ${ }^{10,16}$ After application of the correction, the absorbance is always positive, though negligible above 170 $\mathrm{nm}$, and at $157 \mathrm{~nm}$ a value of $0.31 \mathrm{~cm}^{-1}$ is obtained.

2.4. Sample Description. Several commercial fluoropolyether fluids, differing in both the backbone structure and the chain ends, were considered and analyzed in this work (Table 1). None of these products is specifically designed for optical applications.

The first family consists of perfluorinated polyethers (PFPEs), both linear and branched, having the following structures:

\section{$\mathrm{CF}_{3} \mathrm{O}\left(\mathrm{CF}_{2} \mathrm{CF}_{2} \mathrm{O}\right)_{p}\left(\mathrm{CF}_{2} \mathrm{O}\right)_{q} \mathrm{CF}_{3} \quad$ FOMBLIN Z}

(samples Z1-Z4)

\section{$\mathrm{CF}_{3} \mathrm{O}\left(\mathrm{CF}_{2} \mathrm{CF}\left(\mathrm{CF}_{3}\right) \mathrm{O}\right)_{m}\left(\mathrm{CF}_{2} \mathrm{O}\right)_{n} \mathrm{CF}_{3} \quad$ FOMBLIN Y}

(sample Y1)

\section{$\mathrm{CF}_{3} \mathrm{CF}_{2} \mathrm{CF}_{2} \mathrm{O}\left(\mathrm{CF}\left(\mathrm{CF}_{3}\right) \mathrm{CF}_{2} \mathrm{O}\right)_{p} \mathrm{CF}_{2} \mathrm{CF}_{3} \quad$ KRYTOX}

(sample K1)

\section{$\mathrm{CF}_{3} \mathrm{CF}_{2} \mathrm{CF}_{2} \mathrm{O}\left(\mathrm{CF}_{2} \mathrm{CF}_{2} \mathrm{CF}_{2} \mathrm{O}\right)_{p} \mathrm{CF}_{2} \mathrm{CF}_{3}$ DEMNUM}

(sample D1)

FOMBLIN Z and FOMBLIN Y are the registered trade names of linear and branched PFPEs produced by Solvay-Solexis, KRYTOX is the trade name of the branched PFPE manufactured by Du Pont, and DEMNUM is the linear PFPE by Daikin. The syntheses and the main physical chemical characteristics of these commercial PFPEs have been extensively described in the literature. ${ }^{12,14}$

Another family of commercial linear fluoropolyethers considered here contains hydrogen in the chain ends as $-\mathrm{OCF}_{2} \mathrm{H}$ or $-\mathrm{OCF}_{2} \mathrm{CH}_{2} \mathrm{OH}$ groups. These compounds, manufactured by 
TABLE 1: Structure and Main Properties of Commercial Fluoropolyether Samples

\begin{tabular}{|c|c|c|c|c|c|c|c|c|}
\hline sample & $\begin{array}{c}\mathrm{OC}_{1}{ }^{a} \\
(\% \mathrm{~mol})\end{array}$ & $\begin{array}{c}\mathrm{OC}_{2}^{a} \\
(\% \mathrm{~mol})\end{array}$ & $\begin{array}{c}\mathrm{OC}_{3, \text { lin }}{ }^{a} \\
(\% \mathrm{~mol})\end{array}$ & $\begin{array}{c}\mathrm{OC}_{3, \mathrm{br}}{ }^{a} \\
(\% \mathrm{~mol})\end{array}$ & $\begin{array}{c}M_{n} \\
\left({ }^{19} \mathrm{~F} \text { NMR }\right)\end{array}$ & $\begin{array}{c}\text { viscosity } \\
\left(\mathrm{cSt} @ 20^{\circ} \mathrm{C}\right)\end{array}$ & $\begin{array}{c}\text { chlorine } \\
\left(\text { mequiv } \mathrm{kg}^{-1} \text { ) }\right.\end{array}$ & $\begin{array}{c}A_{157} \\
\left(\mathrm{~cm}^{-1}\right)\end{array}$ \\
\hline Z1 & 50 & 50 & & & 3900 & 36 & 21.0 & 3.2 \\
\hline $\mathrm{Z} 2$ & 52 & 48 & & & 15200 & 260 & 26.6 & 5 \\
\hline Z3 & 51 & 49 & & & 15100 & 280 & 71.8 & 11.7 \\
\hline Z4 & 50 & 50 & & & 19700 & 600 & 38.3 & 7.5 \\
\hline Y1 & $6^{b}$ & & & 94 & 4200 & 250 & & 14.8 \\
\hline K1 & & & & $99^{c}$ & 3300 & 260 & & 2.8 \\
\hline D1 & & & 100 & & 4750 & 150 & & 2.6 \\
\hline H-ZT1 & 30 & 70 & & & 460 & 0.9 & & 5.9 \\
\hline H-ZT2 & 28 & 72 & & & 630 & 1.5 & & 4.5 \\
\hline H-ZT3 & 32 & 68 & & & 1304 & 6.2 & & 2.9 \\
\hline H-ZT4 & 10 & 90 & & & 790 & 2 & & 4.7 \\
\hline ZD1 & & & & & & & & $>100$ \\
\hline DM1 & & 100 & & & 162 & 0.7 & & $>100$ \\
\hline DM2 & & 100 & & & 278 & 1.3 & & $>100$ \\
\hline
\end{tabular}

${ }^{a} \mathrm{OC}_{1}=-\mathrm{OCF}_{2}-$ units; $\mathrm{OC}_{2}=-\mathrm{OCF}_{2} \mathrm{CF}_{2}-$ units; $\mathrm{OC}_{3, \text { lin }}=-\mathrm{OCF}_{2} \mathrm{CF}_{2} \mathrm{CF}_{2}-$ units; $\mathrm{OC}_{3, \text { br }}=-\mathrm{OCF}\left(\mathrm{CF}_{3}\right) \mathrm{CF}_{2}-$ units. $^{b}-\mathrm{OCF} \mathrm{F}_{2}-+-\mathrm{OCF}\left(\mathrm{CF}_{3}\right)-$ units. ${ }^{c}$ Contains $1 \%-\mathrm{OCF}_{2} \mathrm{CF}\left(\mathrm{CF}_{3}\right) \mathrm{CF}\left(\mathrm{CF}_{3}\right) \mathrm{CF}_{2}-$ branched structures.

TABLE 2: Main Characteristics of FOMBLIN Z Optical Grade Samples

\begin{tabular}{ccccccc}
\hline sample & $\begin{array}{c}\mathrm{OC}_{1}{ }^{a} \\
(\% \mathrm{~mol})\end{array}$ & $\begin{array}{c}\mathrm{OC}_{2}{ }^{a} \\
(\% \mathrm{~mol})\end{array}$ & $\begin{array}{c}\mathrm{OC}_{3,4}{ }^{a} \\
(\% \mathrm{~mol})\end{array}$ & $\begin{array}{c}M_{n} \\
\left({ }^{19} \mathrm{~F} \mathrm{NMR}\right)\end{array}$ & $\begin{array}{c}\text { viscosity } \\
\left(\mathrm{cSt} @ 20{ }^{\circ} \mathrm{C}\right)\end{array}$ & $\begin{array}{c}\text { refractive index } \\
(\lambda=589 \mathrm{~nm})\end{array}$ \\
\hline ZOG 1 & 76 & 23 & 1 & 3600 & 19 & 0.35 \\
ZOG 2 & 74 & 25 & 1 & 2467 & 13 & 1.288 \\
ZOG 3 & 60 & 38 & 2 & 19400 & 650 & 1.293 \\
ZOG 4 & 29 & 63 & 8 & 11600 & 230 & 1.289 \\
ZOG 5 & 28 & 65 & 7 & 4000 & 30 & 1.286 \\
ZOG 6 & 25 & 68 & 7 & 2863 & 23 & 0.5 \\
${ }^{a} \mathrm{OC}_{1}=-\mathrm{OCF}_{2}-$ units; $\mathrm{OC}_{2}=-\mathrm{OCF}_{2} \mathrm{CF}_{2}-$ units; $\mathrm{OC}_{3,4}=-\mathrm{OCF}_{2} \mathrm{CF}_{2} \mathrm{CF}_{2}-$ and $\mathrm{OCF}_{2} \mathrm{CF}_{2} \mathrm{CF}_{2} \mathrm{CF}_{2}-$ units.
\end{tabular}

Solvay-Solexis, have the following structures:

$$
\begin{array}{r}
\mathrm{HCF}_{2} \mathrm{O}\left(\mathrm{CF}_{2} \mathrm{CF}_{2} \mathrm{O}\right)_{p}\left(\mathrm{CF}_{2} \mathrm{O}\right)_{q} \mathrm{CF}_{2} \mathrm{H} \quad \mathrm{H}-\mathrm{GALDEN} \mathrm{ZT} \\
\text { (samples H-ZT1-H-ZT4) } \\
\mathrm{HOCH}_{2} \mathrm{CF}_{2} \mathrm{O}\left(\mathrm{CF}_{2} \mathrm{CF}_{2} \mathrm{O}\right)_{p}\left(\mathrm{CF}_{2} \mathrm{O}\right)_{q} \mathrm{CF}_{2} \mathrm{CH}_{2} \mathrm{OH} \\
\text { FOMBLIN ZDOL (sample ZD1) }
\end{array}
$$

The syntheses and main properties of these products are described in the literature. ${ }^{17,18}$

Finally two experimental $\alpha, \omega$-dimethoxy fluoropolyethers were also considered to extend the VUV measurements to the $-\mathrm{OCH}_{3}$ end group, maintaining the linear PFPE backbone structure unaltered. Such products have the following structure:

$$
\mathrm{CH}_{3} \mathrm{O}\left(\mathrm{CF}_{2} \mathrm{CF}_{2} \mathrm{O}\right)_{p}\left(\mathrm{CF}_{2} \mathrm{O}\right)_{q} \mathrm{CH}_{3} \quad \text { (samples DM1 and DM2) }
$$

Their syntheses and main properties have been recently published. ${ }^{19}$

Table 1 summarizes the main characteristics of the 14 samples described above (12 commercial and 2 experimental). The structures and the molecular weights of all compounds were determined by ${ }^{19} \mathrm{~F}$ NMR and ${ }^{1} \mathrm{H}$ NMR spectroscopy. The kinematic viscosities were measured using calibrated CannonFenske viscometers thermostated at $20^{\circ} \mathrm{C}$.

On the basis of the results obtained by the VUV absorption measurements on these commercial products, a new family of linear perfluoropolyethers was specifically synthesized for optical applications. ${ }^{20,21}$ These compounds, named FOMBLIN ZOG, have been prepared using a specific methodology that prevents the formation of end groups containing chlorine, which, although present in very limited amounts in the samples reported in Table 1, were found to have a strong impact on the VUV absorption.

2.5. Synthesis of the FOMBLIN ZOG Samples. All compounds reported in Table 2, except sample ZOG3, have been
SCHEME 1: FOMBLIN ZOG Synthesis

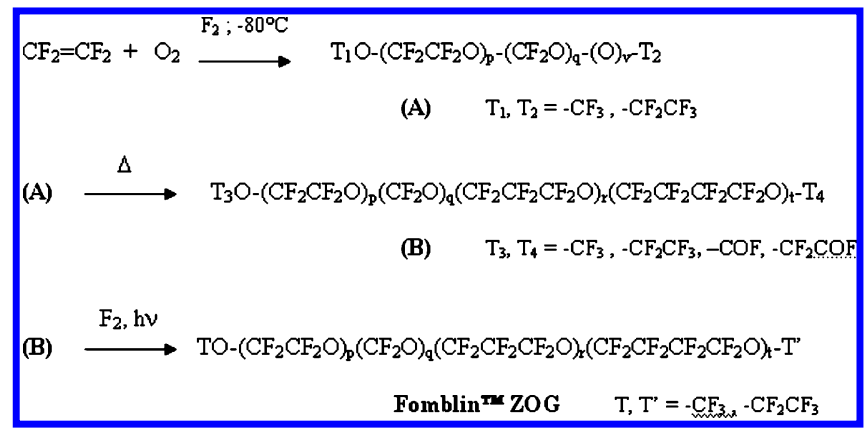

prepared using the chemically initiated oxypolymerization of tetrafluoroethylene (TFE) with fluorine as the radical initiator and the mixture $\mathrm{CF}_{2} \mathrm{Cl}_{2} / \mathrm{COF}_{2}$ as the reaction solvent. ${ }^{20,22}$ The reaction leads to the perfluoropolyether polyperoxide (A) (Scheme 1).

Sample ZOG3 was prepared using the photochemically initiated oxypolymerization of TFE at low temperature using a hydrofluorocarbon solvent (HFC 227ea; $\mathrm{CF}_{3} \mathrm{CFHCF}_{3}$ ) in the presence of elemental fluorine as molecular weight regulator. ${ }^{20}$

The intermediate obtained from the photooxidation of TFE has the same structure of the intermediate (A) but contains small amounts of $-\mathrm{COF}$ and $-\mathrm{CF}_{2} \mathrm{COF}$ chain ends.

It should be noted that both of these synthetic technologies do not introduce chlorinated chain ends in the polymer.

The polyether-polyperoxide intermediates (A) obtained by both techniques were then submitted to thermal treatments at temperatures ranging from 160 to $230{ }^{\circ} \mathrm{C}$, using fluorine as a molecular weight regulator when necessary, to remove the peroxide groups and obtain the intermediate perfluoropolyether (B) (Scheme 1).

Finally, the photochemical fluorination of compound B converts all functionalized end groups into stable perfluorinated chain ends. The obtained compounds were in some cases 


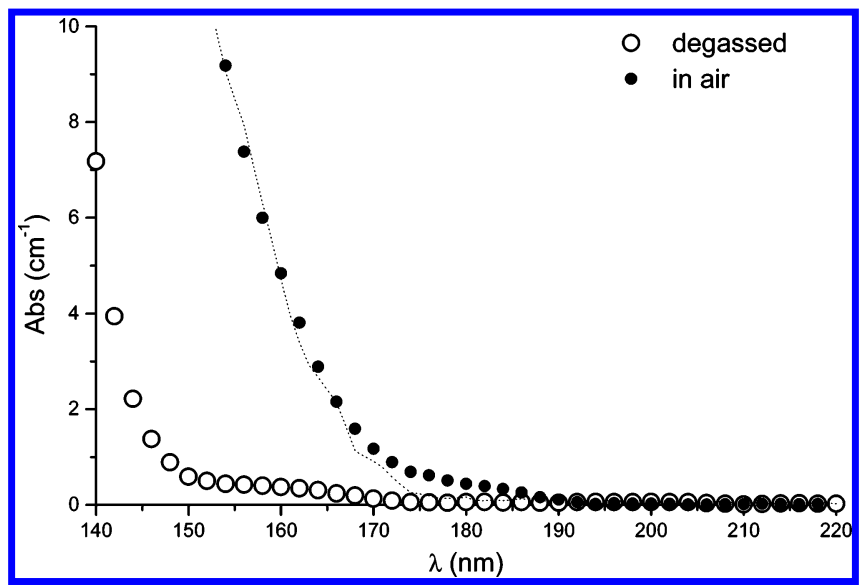

Figure 2. Absorption behavior of the experimental sample ZOG 1 before and after degassing. The dotted line is obtained by adding to the experimental data of the degassed sample the contribution corresponding to about $60 \mathrm{ppm}$ of dissolved molecular oxygen.

distilled by molecular distillation to obtain the desired average molecular weight and viscosity. Table 2 reports the main characteristics of the six experimental FOMBLIN ZOG samples synthesized.

2.6. Air Removal from Fluids. Particular care was taken to remove air from the fluids. Molecular oxygen can have a deleterious effect on accurate determination of PFPE absorption at $157 \mathrm{~nm}$, as it has a high partial pressure in air and is highly soluble and strongly absorbing in VUV region. Oxygen solubility in PFPE fluids has been reported, as Bunsen coefficients, in the range of $0.2-0.4,{ }^{12}$ corresponding to about $2-4 \times 10^{-6}$ $\mathrm{mol} / \mathrm{cm}^{3}$, while the oxygen absorption cross section at $157 \mathrm{~nm}$ is $6.7 \times 10^{-18} \mathrm{~cm}^{2} .{ }^{23}$ Other gases have less impact on the VUV absorbance, having a low partial pressure $\left(\mathrm{CO}_{2}\right)$, poor solubility $\left(\mathrm{H}_{2} \mathrm{O}\right)$, or low absorption $\left(\mathrm{N}_{2}\right)$.

Atmospheric gases have been accurately removed by applying several cycles of freeze-thawing between 80 and $300 \mathrm{~K}$ under vacuum. Then, the samples have been sealed in special tubes and transferred immediately before the measurements in the experimental sealed cell under a drybox flushed with nitrogen.

Figure 2 shows the behavior of the sample ZOG 1 measured before and after the degassing procedure. The presence of atmospheric oxygen strongly affects the absorbance at $157 \mathrm{~nm}$. The dotted line is obtained by adding the theoretical contribution (cross section data taken from ref 22) corresponding to $60 \mathrm{ppm}$ of molecular oxygen to the experimental data of the degassed sample. This result matches the experimental sample before degassing. Similar results are obtained for all the investigated samples.

2.7. Theoretical HOMO-LUMO Gap Calculations. Ab initio calculations were performed using density functional theory (DFT), as implemented in DMOL3 (Accelrys Inc.), at medium/fine level of accuracy and using the double numerical basis set (DND or DNP) and the Becke-Lee-Yang-Parr (BLYP) nonlocal functional. ${ }^{24,25}$ This functional was used because it was reported in the literature to give reliable results on perfluoropolyether compounds. ${ }^{26,27}$

\section{Results and Discussion}

3.1. Theoretical Calculations: Dependence of the Optical Absorption on the Perfluoroether Structure and Chain End Composition. The first step in this work was devoted to obtaining some general rules from ab initio calculations of the

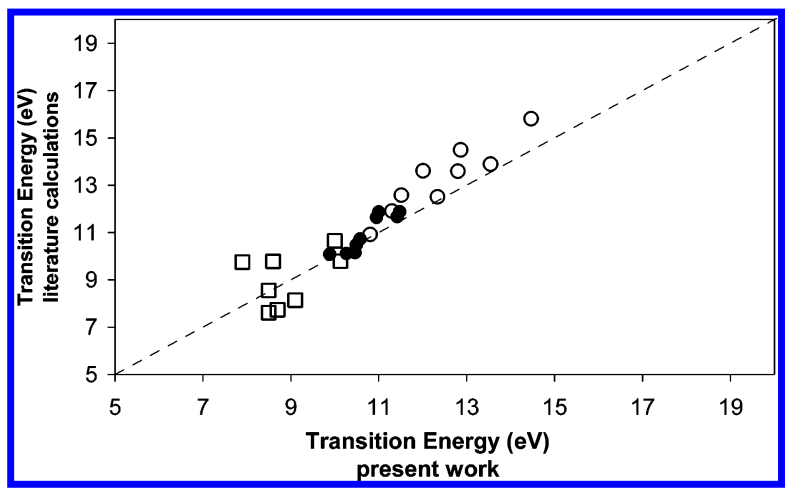

Figure 3. Comparison of some ab initio calculations obtained in this work with literature results on the same structure (see text).

TABLE 3: Effect of Oxygen Substitution on the HOMO-LUMO Transition Energy $\left(E_{\mathrm{HL}}\right)$ in Linear Perfluoralkanes

\begin{tabular}{llr}
\hline & $\begin{array}{c}\text { backbone } \\
\text { atoms }\end{array}$ & $E_{\mathrm{HL}}(\mathrm{eV})$ \\
\hline $\mathrm{CF}_{3} \mathrm{CF}_{2} \mathrm{CF}_{3}$ & 3 & 8.6 \\
$\mathrm{CF}_{3}-\mathrm{O}-\mathrm{CF}_{3}$ & 3 & 10.6 \\
$\mathrm{CF}_{3}\left(\mathrm{CF}_{2}\right)_{2} \mathrm{CF}_{3}$ & 4 & 7.9 \\
$\mathrm{CF}_{3}-\mathrm{O}-\mathrm{CF}_{2}-\mathrm{CF}_{3}$ & 4 & 9.5 \\
$\mathrm{CF}_{3}\left(\mathrm{CF}_{2}\right)_{3} \mathrm{CF}_{3}$ & 5 & 7.3 \\
$\mathrm{CF}_{3} \mathrm{CF}_{2}-\mathrm{O}-\mathrm{CF}_{2} \mathrm{CF}_{3}$ & 5 & 9.1
\end{tabular}

HOMO-LUMO transition energy $\left(E_{\mathrm{HL}}\right)$ to reduce the number of possible variables to be experimentally tested. Both structural variables (oxygen-to-carbon ratio and length of difluoromethylene sequences, lateral groups) and extrinsic variables (impurities, chain ends) could play a role in absorption at very low wavelengths.

A comparison of our calculations with several published experimental and theoretical calculations on structures similar to those reported in this study is shown in Figure 3. Open symbols refer to partially and fully fluorinated alkanes ${ }^{28}$ and closed symbols refer to the lowest energy transitions of $\mathrm{CF}_{3}-$ $\mathrm{OCF}_{3}$ and $\mathrm{CF}_{3} \mathrm{OCF}_{2} \mathrm{H} .{ }^{16}$ The major results of these tests is that within homogeneous classes of materials reasonable and consistent results can be obtained in an efficient way. Therefore, though a detailed comparison of calculational methods and software is beyond the scope of this work, it is our belief that the HOMO-LUMO transition energies could be a useful guide for our experimentation. It is also useful to recall that for small chain molecules the effect of chain length on calculated transition energy is not negligible; ${ }^{11}$ therefore in the following comparison the number of backbone atoms must always be considered.

The major structural difference between perfluoroalkanes and perfluoropolyether is the presence of oxygen atoms in the backbone. The effect of the substitution of a $-\mathrm{CF}_{2}-$ with oxygen is illustrated in Table 3 for three different chain lengths, and it is evident that the introduction of an oxygen atom induces a substantial increase of $E_{\mathrm{HL}}(\sim 2 \mathrm{eV})$, independently of the chain length. Though these results are in qualitative agreement with literature data obtained from different sources, ${ }^{16,28}$ we have indeed found a significant influence of oxygen in the HOMOLUMO energy gap and consequently in the absorption at 157 $\mathrm{nm}$ of the perfluoropolyethers examined in this study.

The introduction of oxygen in normal alkanes has a reverse effect from that in fluorinated alkanes, inducing a strong decrease of energy gap. In fact, $E_{\mathrm{HL}}$ values for $\mathrm{CH}_{3} \mathrm{CH}_{2} \mathrm{CH}_{3}$ and $\mathrm{CH}_{3} \mathrm{OCH}_{3}$ have been calculated to be about 8.7 and 6.6 $\mathrm{eV}$, respectively. 
TABLE 4: Effect of Side Perfluomethyl Groups on the HOMO-LUMO Transition Energy $\left(E_{\mathrm{HL}}\right)$ in Linear Perfluoralkanes and PFPE

\begin{tabular}{lcc}
\hline & $\begin{array}{c}\text { backbone } \\
\text { atoms }\end{array}$ & $E_{\mathrm{HL}}(\mathrm{eV})$ \\
\hline $\mathrm{CF}_{3}-\mathrm{O}-\mathrm{CF}_{2}-\mathrm{CF}\left(\mathrm{CF}_{3}\right)-\mathrm{O}-\mathrm{CF}_{3}$ & 6 & 7.8 \\
$\mathrm{CF}_{3}-\mathrm{O}-\mathrm{CF}_{2}-\mathrm{CF}_{2}-\mathrm{O}-\mathrm{CF}_{3}$ & 6 & 9.2 \\
$\mathrm{CF}_{3}-\mathrm{O}-\mathrm{CF}_{2}-\mathrm{CF}_{2}-\mathrm{CF}_{2}-\mathrm{O}-\mathrm{CF}_{3}$ & 7 & 8.4 \\
$\mathrm{CF}_{3} \mathrm{CF}_{2} \mathrm{CF}\left(\mathrm{CF}_{3}\right) \mathrm{CF}_{2} \mathrm{CF}_{3}$ & 5 & 7.2 \\
$\mathrm{CF}_{3}\left(\mathrm{CF}_{2}\right)_{3} \mathrm{CF}_{3}$ & 5 & 7.3 \\
$\mathrm{CF}_{3}\left(\mathrm{CF}_{2}\right)_{4} \mathrm{CF}_{3}$ & 6 & 6.9
\end{tabular}

TABLE 5: Effect of Chain End Groups on the HOMO-LUMO Transition Energy $\left(E_{\mathrm{HL}}\right)$ in Linear PFPE

\begin{tabular}{lc}
\hline & $E_{\mathrm{HL}}(\mathrm{eV})$ \\
\hline $\mathrm{CF}_{3}-\mathrm{O}-\mathrm{CF}_{2}-\mathrm{CF}_{3}$ & 9.5 \\
$\mathrm{CF}_{3}-\mathrm{CF}_{2}-\mathrm{O}-\mathrm{CF}_{2} \mathrm{H}$ & 9.3 \\
$\mathrm{CF}_{3}-\mathrm{O}-\mathrm{CF}_{2}-\mathrm{CF}_{2} \mathrm{H}$ & 8.8 \\
$\mathrm{CF}_{3}-\mathrm{CF}_{2}-\mathrm{O}-\mathrm{CH}_{2} \mathrm{OH}$ & 7.5 \\
$\mathrm{CF}_{3}-\mathrm{O}-\mathrm{CF}_{2}-\mathrm{CH}_{2} \mathrm{OH}$ & 6.9 \\
$\mathrm{CF}_{3}-\mathrm{O}-\mathrm{CF}_{2}-\mathrm{CH}_{2} \mathrm{OCH}$ & 6.8 \\
$\mathrm{CF}_{3}-\mathrm{O}-\mathrm{CF}_{2}-\mathrm{CH}_{3}$ & 8.2 \\
$\mathrm{CF}_{3}-\mathrm{CF}_{2}-\mathrm{O}-\mathrm{CF}_{2} \mathrm{Cl}$ & 6.5 \\
$\mathrm{CF}_{3}-\mathrm{O}-\mathrm{CF}_{2}-\mathrm{CF}_{2} \mathrm{Cl}$ & 6.6
\end{tabular}

Increasing the chain length the interpretation of results is more difficult mainly because several oxygen atoms can be located in different positions within the chain. However, we have found that the presence of sequences having three or more $-\mathrm{CF}_{2}-$ groups lowers $E_{\mathrm{HL}}$ and equivalently increases the absorption wavelength. A useful example is the comparison between the two isomers $\mathrm{CF}_{3} \mathrm{CF}_{2}-\mathrm{O}-\mathrm{CF}_{2}-\mathrm{O}-\mathrm{CF}_{2} \mathrm{CF}_{3}$ and $\mathrm{CF}_{3}-\mathrm{O}-\mathrm{CF}_{2}-$ $\mathrm{CF}_{2}-\mathrm{CF}_{2}-\mathrm{O}-\mathrm{CF}_{3}$ that have energy gaps of 9.0 and $8.4 \mathrm{eV}$, respectively. The effect of short perfluoromethylene sequences has already been investigated in mixed hydrogenated and fluorinated alkanes, containing no oxygen atoms. ${ }^{29}$ It is reported that $-\mathrm{CF}_{2}-\mathrm{CF}_{2}-\mathrm{CF}_{2}-\mathrm{CF}_{2}-$ induces a substantial red shift and a marked increased in absorbance at $157 \mathrm{~nm}$ and that $-\mathrm{CF}_{2}-$ $\mathrm{CF}_{2}-$ has a slightly lower absorbance than $-\mathrm{CF}_{2}-$ and $-\mathrm{CF}_{2}-$ $\mathrm{CF}_{2}-\mathrm{CF}_{2}-$. Therefore, ab initio calculations indicate that the presence of long $-\mathrm{CF}_{2}-$ sequences is not beneficial for transparency in the VUV region for both perfluoroalkanes and perfluoropolyethers.

In addition to other possible structural variations, the influence of side perfluoromethyl groups $\left(-\mathrm{CF}_{3}\right)$ was also theoretically investigated. Table 4 shows some structures to illustrate this effect. These structures are compared with linear molecules having the same number of atoms in the backbone but also with their linear isomers. In the case of PFPE, the presence of side $-\mathrm{CF}_{3}$ groups has a negative effect, decreasing the energy gap and therefore increasing the absorption wavelength, whereas in perfluoroalkanes the effect is much less evident.

Among extrinsic variables, we focused our investigation on chain ends. Major results on relevant groups are reported in Table 5. Though all these groups decrease the energy gap, it is particularly relevant for $-\mathrm{CH}_{2} \mathrm{OH},-\mathrm{CH}_{2} \mathrm{OCH}_{3}$, and $-\mathrm{CF}_{2} \mathrm{Cl}$. Therefore, a number of PFPE derivatives have been discarded before testing, and the best synthetic route could be forecast, as shown in the next section.

3.2. Absorbance Measurements on Commercial Samples. The indications stemming both from the literature and from our calculations convinced us to restrict the experimental measurements to the perfluoropolyether family, in particular those having the linear (unbranched) backbone structure. Several commercial products belonging to this class of compounds with different chain ends were therefore considered; in addition some PFPEs with branched structures (Y1, K1) or longer carbon sequences (D1) were evaluated for comparison.

The absorbance measurements at $157 \mathrm{~nm}$ performed on the commercial degassed PFPE samples are reported in Table 1. All these values are significantly higher than those reported in the literature for the perfluorotriglyme. ${ }^{10}$ In particular, samples ZD1, DM1, and DM2 have the highest absorbance; since they have the same backbone structure as the $\mathrm{Z}$ and $\mathrm{H}-\mathrm{ZT}$ samples, very likely the chain ends $-\mathrm{OCF}_{2} \mathrm{CH}_{2} \mathrm{OH}$ and $-\mathrm{OCH}_{3}$ strongly contribute to the overall VUV absorbance, in agreement with the theoretical calculations. The interpretation of the other data is less straightforward, since the samples differ for both the backbone structure and the chain ends. The lowest values obtained are those of samples Z1 and H-ZT3, which have the linear perfluoromethyleneoxy/perfluoroethyleneoxy backbone structure but different chain ends. Within the H-ZT series the absorbance values seem to correlate with the reciprocal of the molecular weight, indicating a possible influence of the $-\mathrm{OCF}_{2} \mathrm{H}$ chain ends.

This correlation is not found in the $\mathrm{Z}$ series. However, the ${ }^{19} \mathrm{~F}$ NMR analyses of the Z1-Z4 samples indicates, besides the perfluoroalkyl chain ends, the presence of chlorinated chain ends with structures $-\mathrm{OCF}_{2} \mathrm{Cl}$ and $-\mathrm{OCF}_{2} \mathrm{CF}_{2} \mathrm{Cl}$, which are quantified by integration of the corresponding NMR signals and comparison with the backbone signals. The obtained values are reported in Table 1, expressed as milliequivalents of chlorinated chain ends per kilogram of PFPE, and correlate with the absorbance values of the $\mathrm{Z}$ series.

Therefore, for both the $\mathrm{Z}$ and the H-ZT series the absorbance at $157 \mathrm{~nm}$ seems to depend mostly on the amount of chain ends, whereas the linear perfluoromethyleneoxy/perfluoroethyleneoxy backbone structure seems to have a high transparency.

Conversely, ${ }^{19} \mathrm{~F}$ NMR indicated that samples Y1, K1, and D1 have only perfluorinated chain ends, and therefore the observed absorption should be due exclusively to the backbone chain. The higher absorbance of the branched perfluoropolyether structure compared with the linear structure is in agreement with the previous literature data ${ }^{10}$ and with our calculations.

3.3. Dependence of the Optical Absorption on the Chain Ends. To check the suggestions arising both from the theoretical calculations and from the measurements on commercial samples, we synthesized linear PFPEs bearing only perfluoroalkyl chain ends. Chlorinated chain ends are always present in commercial $\mathrm{Z}$ samples due to the specific synthetic route, which involves the photooxidation of tetrafluoroethylene at low temperature in the solvent $\mathrm{CF}_{2} \mathrm{Cl}_{2}$, using the UV light emitted by a highpressure Hg lamp (200-350 nm). ${ }^{14}$ Though the chlorofluorocarbon (CFC) solvent is essentially transparent in this UV region, its marginal absorbance at wavelengths close to $200 \mathrm{~nm}$ produces the photodissociation of a small amount of $\mathrm{CF}_{2} \mathrm{Cl}_{2}$ molecules. The chlorinated radicals thus formed are able to initiate new polymer chains, and therefore they are finally found in the peroxidic polymer intermediate as chain ends. Since they are extremely stable under both thermal and fluorination conditions, they survive in the final PFPE product, which generally contains from 20 to 50 mequiv $/ \mathrm{kg}$ of chlorinated chain ends.

To avoid the formation of these species in the photochemical process it was necessary to use a non-chlorinated solvent. Sample ZOG 3 (Table 2) was in fact obtained using the photooxidation technology in the presence of the solvent $\mathrm{CF}_{3}$ $\mathrm{CFHCF}_{3}$ (HFC 227ea). ${ }^{20}$ 


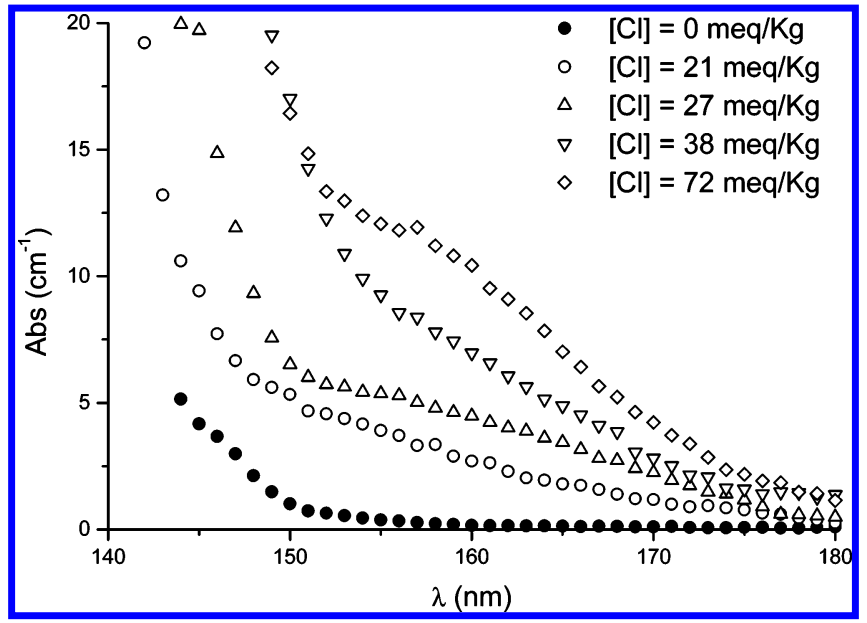

Figure 4. Absorption of linear PFPE with different chlorinated chain ends contents. The circles refer to the experimental sample ZOG 2. Samples have been degassed prior to the measurement.

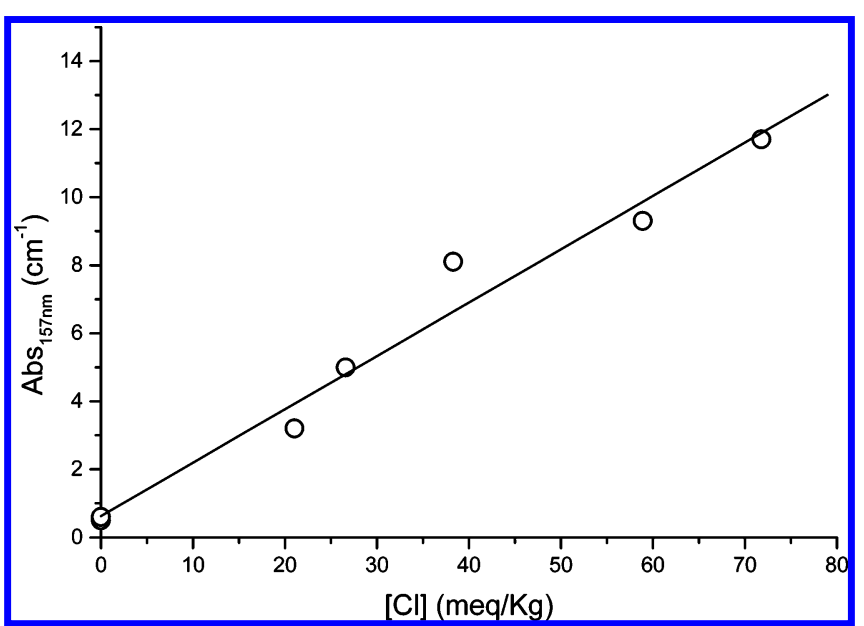

Figure 5. Dependence of the absorbance at $157 \mathrm{~nm}$ on the chlorine content.

All the other samples of Table 2 were prepared by the chemically initiated oxypolymerization technique, using fluorine as the initiator and the mixture $\mathrm{CF}_{2} \mathrm{Cl}_{2} / \mathrm{COF}_{2}$ as the reaction solvent. Even though the polymerization solvent was CFC, no chlorine was found in the peroxidic intermediates. ${ }^{22}$ This result clearly indicates that no chlorine radical transfer reaction takes place in the "dark" process and that the chlorinated solvent must be avoided only when the photochemical technique is used.

Figure 4 shows the absorption spectra in the 140-180 nm region of the commercial $\mathrm{Z} 1-\mathrm{Z} 4$ samples in comparison with the experimental sample ZOG 2. A band of variable intensity is clearly visible in the $150-160 \mathrm{~nm}$ region that progressively decreases with the content of chlorine and finally disappears in the experimental sample, which shows a flat absorption down to $150 \mathrm{~nm}$. This absorption band can be reasonably simulated by a Gaussian curve peaked at $155 \mathrm{~nm}$ and a constant width of $12 \mathrm{~nm}$ for all the samples. Therefore, the maximum of absorption is very close to the $157 \mathrm{~nm}$ wavelength of interest for lithography.

Assuming that this absorption band is associated with chlorine, it is possible to calculate the absorption cross section at $157 \mathrm{~nm}$ from the experimental spectra. Figure 5 reports the optical density at $157 \mathrm{~nm}$ as a function of the chlorine content for the Z1-Z4 samples, having the same backbone structure $(p / q \approx 1)$. The optical density linearly extrapolates to a value of about $0.5 \mathrm{~cm}^{-1}$ in the absence of chlorine. This value can be assumed from the intrinsic absorption of the linear PFPE

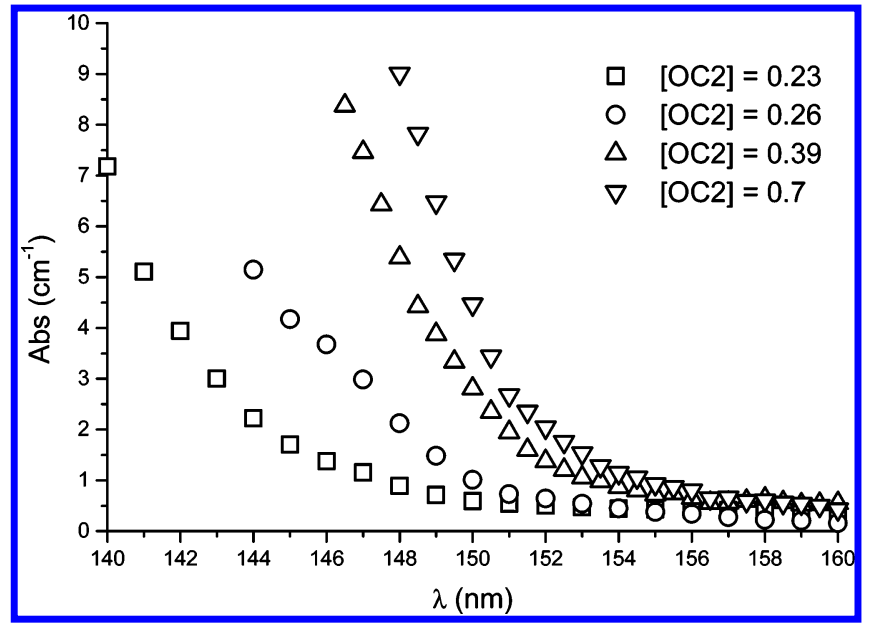

Figure 6. Absorption of experimental ZOG samples with variable molar fractions of $-\mathrm{OC} 2-$ units. Samples have been degassed prior to the measurement.

polymer, in accordance with the values obtained for the experimental ZOG1-ZOG6 samples. From the slope of the fitting line, the contribution of the chlorine to the absorption at $157 \mathrm{~nm}$ is $0.16 \mathrm{~cm}^{-1} /($ mequiv $/ \mathrm{kg})(\mathrm{Cl})$, equivalent to an absorption cross section of $1.5 \times 10^{-19} \mathrm{~cm}^{2}$.

This assignment is in agreement with the literature data on other fluorinated compounds. In the far-UV region, chlorofluoromethanes have been reported to have a pair of absorption bands associated with two different transitions. ${ }^{30-32}$ In the gaseous phase a weaker absorption $(\epsilon=10-100)$ occurs at wavelengths of about $140-170 \mathrm{~nm}$ while a stronger band $(\epsilon>$ $10000)$ is present at $120-140 \mathrm{~nm}$. The former has been associated with a $n-\sigma^{*}$-type transition from the lone pair electrons of the $\mathrm{Cl}$ atoms to a valence-shell-type antibonding orbital in the $\mathrm{C}-\mathrm{Cl}$ bond, while the latter has been associated with an atomic $n$ s Rydberg series, related to the excitation of $\mathrm{Cl}$ lone pairs to a $3 \mathrm{~s}$ level. ${ }^{30}$ Chlorofluoroethanes are also reported to absorb in the far-UV region, starting from 220 nm. ${ }^{31,32}$

Using the experimental data of samples H-ZT1-H-ZT4, we have also been able to calculate the contribution of the $-\mathrm{CF}_{2} \mathrm{H}$ chain ends to the $157 \mathrm{~nm}$ absorption. From the dependence of the absorption values on the hydrogen content, this contribution is estimated to be $1.4 \times 10^{-3} \mathrm{~cm}^{-1} / \mathrm{ppm}(\mathrm{H})$, equivalent to an absorption cross section of $1.3 \times 10^{-21} \mathrm{~cm}^{2}$ per hydrogen atom.

3.4. Dependence of the Optical Absorption on the Perfluoroether Linear Structure. Having identified the linear PFPE structure with perfluorinated chain ends as the most transparent structure in the VUV region, we have tried to understand the effect of the backbone composition $\left(-\mathrm{CF}_{2}-\right.$ $\mathrm{CF}_{2} \mathrm{O}-/-\mathrm{CF}_{2} \mathrm{O}-$ ratio) on the optical absorption of these molecules. For this purpose the experimental ZOG samples (with perfluorinated chain ends) have been synthesized with variable backbone compositions and molecular weights (Table 2), and their optical absorptions were measured in the VUV region. Figure 6 shows the optical absorbance of four ZOG samples with different molar fraction $-\mathrm{CF}_{2} \mathrm{CF}_{2} \mathrm{O}-$ units ([OC2]). The values at $193 \mathrm{~nm}\left(<0.1 \mathrm{~cm}^{-1}\right)$ and at $157 \mathrm{~nm}\left(0.3-0.6 \mathrm{~cm}^{-1}\right)$ are very similar, but the different steepness of the absorption tail below $157 \mathrm{~nm}$ indicates that the optical threshold depends on polymer composition. A series of functions have been proposed $^{33}$ to describe the absorption threshold associated with interband transitions in amorphous materials. Among them, the simple expression for the imaginary part of the dielectric function published by Tauc ${ }^{34}$ and co-workers was chosen to fit 


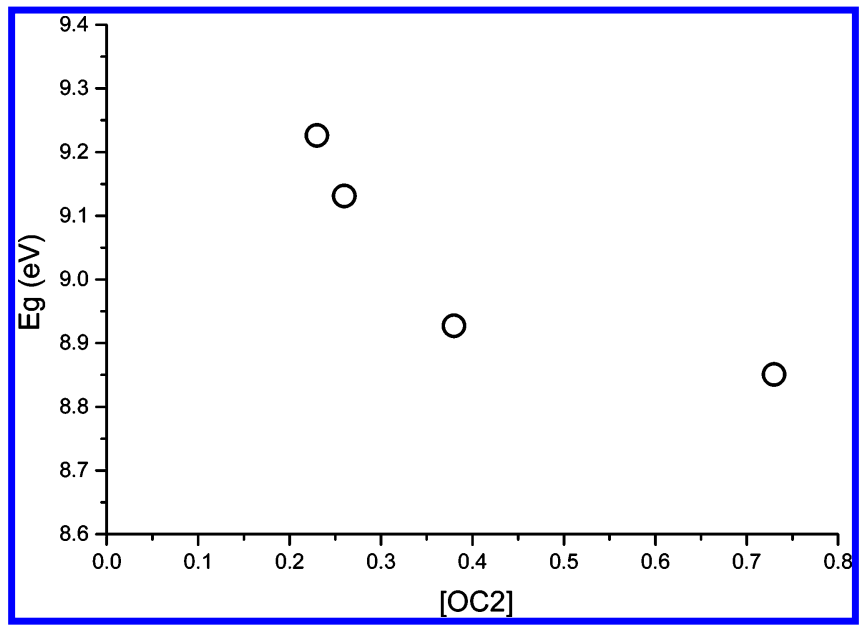

Figure 7. Dependence of the energy gap $E_{g}$ on $-\mathrm{OC} 2-$ content.

the experimental absorption thresholds

$$
\epsilon_{2}(E)=\mathrm{A}\left(E-E_{\mathrm{g}}\right)^{2} / E^{2}
$$

where $\epsilon_{2}=2 n k$ is the imaginary part of the dielectric constant, $E$ is the photon energy, and $A$ and $E_{\mathrm{g}}$ are two fitting parameters.

Figure 7 shows the dependence of the optical gap $E_{\mathrm{g}}$ on the $-\mathrm{CF}_{2} \mathrm{CF}_{2} \mathrm{O}-$ content in the chain; the increase of the HOMOLUMO gap with decreasing $-\mathrm{CF}_{2} \mathrm{CF}_{2} \mathrm{O}-$ content (and thus increasing the oxygen content in the chain) is consistent with the localization effect imposed by the oxygen atom against the delocalization allowed by a $-\left(\mathrm{CF}_{2}\right)-{ }_{n}$ chain of growing length. Thus, $-\left(\mathrm{CF}_{2} \mathrm{O}\right)-$ appears to be the more transparent segmental unit. To the best of our knowledge, an energy gap greater than $9 \mathrm{eV}$ has never been reported in an organic polymer.

\section{Conclusions}

The theoretical and experimental study on the absorption contributions in the VUV region arising from the backbone structure and the chain end composition resulted in the rules for the molecular architecture of polymeric liquids with high transparencies in the VUV region. Nonperfluorinated chain ends are detrimental to the VUV transparency, and high oxygen-tocarbon ratios in the perfluoroethereal backbone discourage the electronic delocalization along the fluorinated chain and increase the energy gap. From this experimental evidence, a new synthetic route was developed that paves the way to a novel family of linear perfluorinated polyethers with the same low optical absorption on a broad range of molecular weight and thus of fluido-dynamic characteristics. The absorbance of these materials at $157 \mathrm{~nm}$ as low as $0.31 \mathrm{~cm}^{-1}$ would enable, for example, the introduction of the immersion lithography at 157 nm.

Acknowledgment. We thank Professor Franco Marabelli and Marco Moscardini for the valuable help in the VUV absorption measurements. Solvay-Solexis is acknowledged for permission to publish this work.

\section{References and Notes}

(1) Wallace, B. A. J. Synchrotron Radiat. 2000, 7, 289. 107.

(2) Ullaland, O. Nucl. Instrum. Methods Phvs. Res., Sect. A 2005, 553 ,

(3) Albrecht, E.; Baum, G.; Bellunato, T.; Bressan, A.; Dalla Torre, S.; D’Ambrosio, C.; Davenport, M.; Dragicevic, M.; Duarte Pinto, S.; Fauland, P.; Ilie, S.; Lenzen, G.; Pagano, P.; Piedigrossi, D.; Tessarotto, F.; Ullaland, O. Nucl. Instrum. Methods Phvs. Res. Sect. A 2003, 510, 262

(4) Greuters J.; Rizvi, N. H. Proc. SPIE-Int. Soc. Opt. Eng. 2003, 4941, 77.

(5) Perrotet, D.; Amorosi, S.; Richerzhagen, B. Proc. SPIE-Int. Soc. Opt. Eng. 2005, 5961, 596105.

(6) Mulkens, J.; Flagello, D. G.; Streefkerk, B.; Graeupner, P. J. Microlithogr., Microfabr., Microsvst. 2004, 3, 104.

(7) Rothschild, M.; Bloomstein, T. M.; Fedynyshyn, T. H.; Liberman, V.; Mowers, W.; Sinta, R.; Switkes, M.; Grenville, A.; Orvek, K. J. Fluorine Chem. 2003, 122, 3.

(8) Streefkerk, B.; Baselmans, J.; Gehoel-van Ansem, W.; Mulkens, J.; Hoogendam, C.; Hoogendorp, M.; Flagello, D. G.; Sewell, H.; Graupner, P. Proc. SPIE-Int. Soc. Opt. Eng. 2004, 5377, 285.

(9) Lin, B.-J. Proc. SPIE-Int. Soc. Opt. Eng. 2004, 5377, 46.

(10) Kunz, R. R.; Switkes, M.; Sinta, R.; Rothschild, M.; Curtin, J. E.; French, R. H.; Wheland, R. C.; Kao, C.-P. C.; Mawn, M. P.; Lin, L.; Wetmore, P.; Krukonis, V.; Williams, K. J. Microlithogr., Microfabr. Microsyst. 2004, 3, 73 .

(11) Nagayama, K.; Miyamae, T.; Mitsumoto, R.; Ishii, H.; Ouchi, Y.; Seki, K. J. Electron Spectrosc. Relat. Phenom. 1996, 8, 407.

(12) Marchionni, G.; Ajroldi, G.; Pezzin, G. In Comprehensive Polymer Science; Aggarwal, S. L., Russo, S., Eds.; Pergamon Press: London, 1996; 2nd Supplement.

(13) Cantow, M. J. R.; Larrabee, R. B.; Barral, E. M., II.; Butner, R. S.; Cotts, P.; Levy, F.; Ting, T. Y. Makromol. Chem. 1986, 187, 2475.

(14) Sianesi, D.; Marchionni, G.; De Pasquale, R. J. In Organofluorine Chemistry: Principles and Commercial Applications; Banks, R. E., Ed.; Plenum Press: New York, 1994.

(15) Koike, M. Normal incidence monochromators and spectrometers. In Vacuum Ultraviolet Spectroscopv II; Samson, J. A. R., Ederer, D. L., Eds.; Experimental Methods in Physical Sciences 32; Academic Press: New York, 1998; pp 1-20.

(16) Lee, K.; Jockusch, S.; Turro, N. J.; French, R. H.; Wheland, R. C.; Lemon, M. F.; Braun, A. M.; Widerschpan, T.; Dixon, D. A.; Li, J.; Ivan, M.; Zimmerman, P. J. Am. Chem. Soc. 2005, 127, 8320.

(17) Marchionni, G.; Bassi, M.; Fontana, G.; Maccone, P.; Ajroldi, G. J. Fluorine Chem. 1999, 98, 41.

(18) Tonelli, C.; Gavezotti, P.; Strepparola, E. J. Fluorine Chem. 1999 $95,51$.

(19) Avataneo, M.; De Patto, U.; Galimberti, M.; Marchionni, G. $J$ Fluorine Chem. 2005, 126, 633.

(20) Marchionni, G.; Pagano, E.; Guarda, P. A. Eur. Pat. Appl. 1,524, 287 A1, 2005.

(21) Bassi, M.; Guarda, P. A. Eur. Pat. Appl. 1,521,118 A2, 2005.

(22) Marchionni, G.; Guarda, P. A. U. S. Patent 5,744,651, 1998.

(23) Yoshino, K.; Parkinson, W. H.; Ito, K.; Matsui, T. J. Mol. Spectrosc 2005, 229, 238

(24) Becke, A. D. J. Chem. Phvs. 1988, 88, 2547

(25) Lee, C.; Yang, W.; Parr, R. G. Phys. Rev. B 1988, 37, 786

(26) Radice, S.; Causà, M.; Marchionni, G. J. Fluorine Chem. 1998 , 88,127 .

(27) Radice, S.; Tortelli, V.; Causà, M.; Castiglioni, C.; Zerbi, G. $\underline{\text {. }}$ Fluorine Chem. 1999, 95, 105.

(28) Zhan, C.-G.; Dixon, D. A.; Matsuzawa, N. N.; Ishitani, A.; Uda, T. J. Fluorine Chem. 2003, 122, 27.

(29) Waterland, R. L.; Dobbs, K. D.; Rinehart, A. M.; Feiring, A. E.; Wheland, R. C.; Smart, B. E. J. Fluorine Chem. 2003, 122, 37.

(30) Doucet, J.; Sauvageau, P.; Sandorfy, C. J. Chem. Phvs. 1973, 58, 3708 .

(31) Chou, C. C.; Milstein, R. J.; Smith, W. S.; Vera Ruiz, H.; Molina, M. J.; Rowland, F. S. J. Phvs. Chem. 1978, 82, 1.

(32) Talukdar, R.; Mellouki, A.; Gierczak, T.; Burkholder, J. B.; Stuart, A.; McKeen, S. A.; Ravishankara, A. R. J. Phvs. Chem. 1991, 95, 5815.

(33) Jellison, G. E., Jr.; Modine, F. A. Appl. Phys. Lett. 1996, 69, 371. 627. 